\title{
Changeability and agility enablers in one-of-a-kind product development and design processes
}

\author{
M. Varl ${ }^{1}$ J. Duhovnik ${ }^{2} \cdot$ J. $\operatorname{Tavčar}^{3}$ (1)
}

Received: 17 October 2018 / Revised: 11 October 2021 / Accepted: 13 October 2021 / Published online: 31 October 2021

(C) The Author(s) 2021

\begin{abstract}
The smart factories that are already beginning to appear employ a completely new approach to product creation. Smart products are uniquely identifiable and know both their current status and alternative routes to achieving their target state. Smart factories allow individual customer requirements to be met, meaning that even one-off items can be manufactured profitably. In smart industry, dynamic business and engineering processes enable last-minute changes to design and production, delivering the ability to respond flexibly to disruptions and failures on behalf of suppliers. This paper presents a case study of product development and design process renovation according to changeability paradigm in one-of-a-kind industrial environment. It demonstrates how integration of changeability with agile design strategies crucially contribute to improve the operations of a highly individualized product development business. Successful management of 'never-ending' engineering changes appears to be the most important aspect in this field. Contribution of the presented work is a generalized framework that demonstrates how companies in such specific environments can improve competitiveness through the utilization of changeability concepts. The included case study validated the proposed changeability model and offers valuable insights into how to implement this in practice.
\end{abstract}

Keywords One-of-a-kind production · Changeability $\cdot$ Adaptability $\cdot$ Modular design $\cdot$ Platform design $\cdot$ Smart industry

\section{Introduction}

Rough competition in the global marketplace demands highly functional products, high-quality service, shorter delivery lead-time and increased environmental friendliness, all with suitable cost. Although advanced manufacturing technologies can partially address these challenges, advanced design techniques are considered crucial since most design and manufacturing properties of a product are influenced by the design decisions made in the early design stages. Product development (PD) is the process of transforming customer needs into an economically viable product that satisfies those needs. Faced with intensive global

J. Tavčar

joze.tavcar@design.lth.se

1 Kolektor ETRA, d.o.o., Šlandrova ulica 10, 1231 Ljubljana, Slovenia

2 Faculty of Mechanical Engineering, LECAD, University of Ljubljana, Aškerčeva 6, 1000 Ljubljana, Slovenia

3 Faculty of Engineering - LTH, Lund University, Product development, Sölvegatan 26, 22100 Lund, Sweden competition, increasing operational costs, and the rapid pace of technological innovations, business organizations have started to shift their operations towards smart business environments.

There is a number of initiatives that promote smart industry development, including Advanced Manufacturing Partnership 2.0 (AMP, 2014) and Industrial Internet (IIC, 2014) in the USA and Industry 4.0 (Kagermann et al. 2013) in Germany (Liao et al. 2017). Industry 4.0 is focused on creating smart products, procedures and processes. Within a smart factory, self-organizing value chains can be optimized in real time. This requires an appropriate regulatory framework, as well as standardized interfaces and a harmonized business process (Kagermann et al. 2013). Decisions on process adaptions are, in most cases, made by humans currently. In the future, the decision process will be supported by knowledgeable and self-optimizing manufacturing systems (Yan and Xue 2007; Brettel et al. 2014).

Staying competitive demands high responsiveness, especially on the field of supporting late design decisions to narrow down the time gap between design freeze and system delivery. Particularly in small and medium enterprises 
(SMEs), the PD effort is of vital importance to retain product quality with manageable manufacturing costs and fulfilled customer requirements. Frequently, PD teams are undersized due to resource limitations. They are highly dependent on suppliers and required to respond to short development cycles (Chen et al. 2012). This context may lead some decision-making to more conventional alternatives because they are perceived as low risk in the short term, but they can undermine the future of the company in the medium and long term. One possible way out of this gridlock is to develop structured methods and optimize them to create value in the PD activities (Leite et al. 2016). The architecture of a system must remain changeable and evolutionary even after being introduced to the market place because the changing environment and evolving needs will affect its success throughout its entire lifecycle. There has been a recognized paradigm shift in the past two decades from mass production to mass customization. The need for mass customization is based on fragmented demands, heterogeneous niche markets, favourable, high-quality, customized products and services, and shorter product lifecycles. Therefore, the degree of variety supported by standard product platforms and their derivatives, and supported by the possibility of re-using standard components across products, has become crucial for commercial success (Fricke and Schulz 2005).

Due to the complexity, associated cost, and general uncertainty of performing the creative design process, significant value exists in reusing the design information developed in previous design efforts. Many complex engineering systems are developed through modifications of existing ones (Jarratt et al. 2011). In Sciences of the Artificial, Simon (1996) defined the complexity of a product in terms of the connections between its parts and called engineering products 'almost decomposable systems' where connections between parts of a system can never be fully avoided. Many industries, such as the automotive industry, are working on modular designs, with clearly defined interfaces between subsystems, to make integration easier and to facilitate the reuse of sub-systems across a product range. However, deciding the right time and the right parts of the system to implement design flexibility is not a simple task (de Neufville and Scholtes 2011). There is, thus, a need to differentiate between components that are more suitable for standardization and components that are more suitable to absorb future changes in such systems.

Since the introduction of adaptable design, continuous efforts have been made to improve the design method. However, there is particularly limited information available regarding business operations that produce a large number of distinctly different part numbers in limited quantities (Qudrat-Ullah et al. 2012). Lean production encourages the systematic elimination of wastes to produce products and services at the rate of demand. It offers many benefits, such as reduced inventory levels, higher product quality, reduced lead times, higher productivity, and reduced costs. On the other side, agile production is the capability of a manufacturer to operate profitably in an environment of continually and unpredictably changing customer demand (Ghobakhloo and Azar 2018). Agile production is the next step, after lean production, in the evolution from mass production to mass customization. They are two production strategies that can co-exist in one system. Lean production is the most suitable when the demand is predictable, variety is low and volume is high (Potdar et al. 2017). The agile and lean movements have inspired new approaches, and processes have changed (Turner 2017).

Implementation of lean techniques in SMEs' PD teams has specific requests (Leite et al. 2016). Flexible engineering change management (ECM) for rapid engineering changes has been identified as a central enabler for agile PD of physical products (Schuha et al. 2017). Al-Ashaab et al. (2016) developed a tool that helps to identify the actual status of lean principles in PD processes, while the integrated performance measurement framework for lean organization considers all functions within an organization (Sangwa and Sangwan 2018). Following an extensive and systematic research of existing literature, together with the real case study findings, the paper provides a novel contribution to this field as it explores and discusses the idea of adaptable design from the perspective of the smart one-of-a-kind production environment. According to Fricke and Schulz (2005), the four key aspects of changeability are adaptability, robustness, agility, and flexibility. Later in this research, robustness will be omitted due to its complex and broad background (for more, consult the research of Varl et al. 2016). Instead, platforming will be introduced because its principle is directly linked with agile engineering and supports other aspects in a great manner. Adaptability characterizes a system's ability to adapt itself towards changing environments. Adaptable systems deliver their intended functionality under varying operating conditions through changing themselves. That is no changes from external have to be implemented into such systems to cope with changing environments.

The paper evolves the idea of incorporating changeability into an individualized product's architecture. The study sheds light on how to approach such transformation challenges, wherein the presented case study offers valuable insights into how to implement appropriate measurements in a real, highly individualized PD environment. The generalized form of the proposed framework is the main contribution of the article, as it represents a universal solution for such business environments. In Fig. 1, the transition from traditional production A) to agile production B) is shown, where robustness, modularity, flexibility and adaptability compound design for changeability, which is, together with 


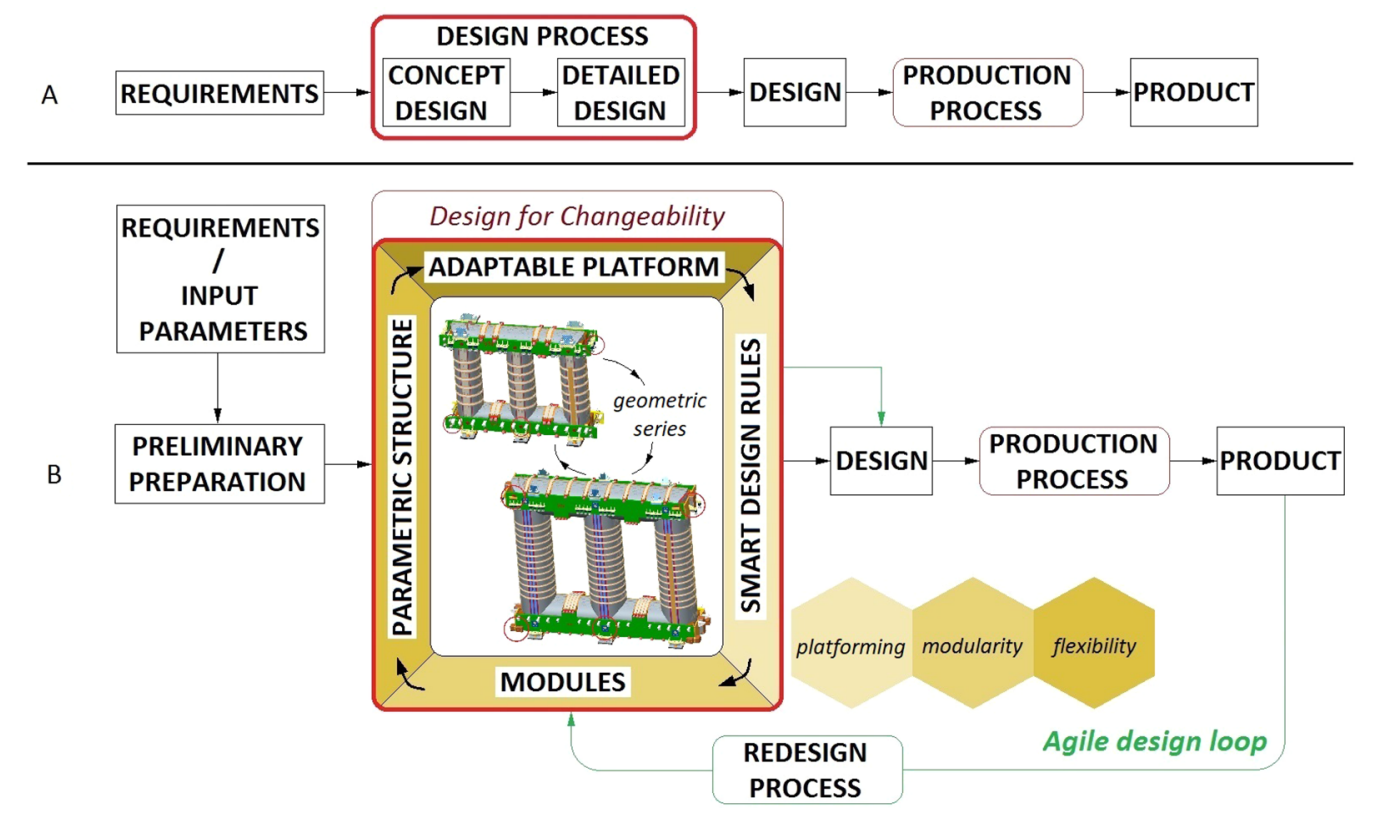

Fig. 1 Transition from traditional production to agile production

parametric structure and smart design rules, a foundation of smart factory and agile business operation. In adaptive design, PD has to be divided into efficient preliminary preparation of design activities and quick adaptation to a specific customer requirements. This preliminary preparation is very important and provides quick responsiveness in the next steps. Design for changeability, which is carried out in the preliminary preparation, is the core of this article because adaptation to specific customer requirements is always subject to intense time and cost pressures.

The paper is organized as follows. Section 2 reviews related research work on agility paradigm, adaptable design, design and product adaptability, smart processes and discusses key issues in adaptable design. In Sect. 3, the generalized framework of one-of-a-kind product development process transformation according to the principles of adaptability is presented. Real industrial background is presented in Sect. 4, explaining phenomena of one-of-a-kind product development process and why adaptive type of design requires creative design process, where significant value exists in reusing existent design information. Core of the paper, the validation of the generalized model represents Sect. 5. Application of changeability in real one-of-a-kind product development is presented via three main principles: flexibility, modularity, and platforming. Each principle is explained through an illustrative example of application to a real industrial environment during the case study. Discussion and assessment is given in Sect. 6 through presentation of list of savings, resulting in PD process according to agile principles. Considerable decrease in engineering changes is also presented. Finally, conclusions are given in Sect. 7.

\section{Literature review}

\subsection{Outbreak of smart industry}

The first three industrial revolutions came about as a result of mechanization, electricity and IT. Now, the introduction of the Internet of Things and Services into the manufacturing environment is ushering in a fourth industrial revolution. Industry 4.0 is focused on creating smart products, procedures and processes (Filho et al. 2017; Lu, 2017). Smart factories, which constitute a key feature of Industry 4.0 , are capable of managing complexity, are less prone to disruption and are able to manufacture goods more efficiently. The learning factory that integrates the shop floor and top floor via suitable cloud services supports holistic, problem-based learning and evaluation of research projects (Faller and Feldmüller, 2015). Wang et al. (2017) argue that the smart factory framework consists of four layers: the physical resource, industrial network, cloud, and supervisory control layers. Big data are collected in the cloud from the smart things in the physical layer and interacts with people through supervisory control. Hermann, Pentek and Otto (2016) identified some generic design principles for Industry 4.0: interconnection, decentralized decisions, information transparency, and technical assistance. By meeting individual customer requirements, a smart design process allows individual, customer-specific criteria to be included in the design, configuration, ordering, planning, manufacture and operation phases and enables last-minute changes to be incorporated. Changeability of a product plays an important role when transforming a traditionally 
designed product into a smart and highly efficient business operation.

\subsection{Agility as a foundation of productivity}

In the last two decades, significant research effort and progress have been made towards the development of fundamental understanding of and effective tools for various aspects of early design processes. One of the representative works is the systematic design approach by Pahl and Beitz (1988). Many design theories and methodologies have been developed and are widely accepted and used in the design of products, processes, and systems. Examples of engineering design research include axiomatic design (Gu et al. 2001; Suh, 2001), function-based design (Pahl and Beitz 1988; Hashemian and $\mathrm{Gu}$ 1996), product family/portfolio architecture, modular and platform design (Siddique and Rosen 2000; Du et al. 2001; Simpson et al. 2001; Simpson et al. 2007; Sand et al. 2002), TRIZ-based design and innovation (Fey and Rivin 2005), design for manufacturing, assembly, services and environment (Dixon and Poli 1995; Martin and Ishii 2000), design reuse (Fletcher and Gu 2005) and concurrent engineering design (Stjepandić, Wognum and Verhagen 2015).

Agility enables the industry to deliver customized, equitably priced, and superior-quality product in an efficient and time-bound manner. It streamlines the internal and external disturbances of the industry that arise due to uncertain market conditions (Leite and Braz, 2016; Potdar et al. 2017). Engineering systems that are adaptable and/or robust to changes do not need to be changed. Alternately, engineering systems that are agile and/or flexible to changes can be changed efficiently by the manufacturer and the user. Fricke and Schulz (2005) also state that it is not necessarily useful to implement all four aspects of changeability throughout the entire system architecture. Instead, attempts to improve system changeability should be guided by the question: 'Where in the system architecture do I need what type of and how much changeability?' As will be demonstrated later, the answer is not trivial; rather, it depends on a number of circumstances.

\subsection{Adaptable design}

Adaptable design (Eckert et al. 2004; Fricke and Schulz, 2005; Gu et al. 2004, 2009; Fletcher and Gu 2005; Tavčar and Duhovnik 2005; Liu et al. 2010) is a relatively new design paradigm that aims to create designs and products that can be easily adapted for different requirements. It is a promising methodology for increasing the potential for the reuse of design information. Adaptable design can generally be divided into design adaptability and product adaptability (Gu et al. 2004). When the design of a product is adaptable, much of the same design can be used to produce new products or modified to adapt to new technologies and demands. The process of adapting an existing design, versus producing new designs, usually results in savings in development time and design and production costs. Although these benefits are mainly for the producer, they also provide the user with more customized products, perhaps at more reasonable costs. If, alternately, the product itself is adaptable, it benefits the user by replacing several products with one or by providing increased functionality.

\subsection{Design adaptability, product adaptability}

Producers are generally concerned with design adaptability because benefits of adaptability result from the fact that one adaptable design can be used to create new products for different customers. Thus, the same basic design, existing common parts and assemblies, process plans, production setups, inventories and supply networks, and expertise can be used in several production scenarios, resulting in reduced costs and development time and increased efficiency. Design adaptability is most applicable to manufacturing companies that produce a family of products with similar functions. Various models can be different adaptations of a basic design where every model includes a different set of features and functionalities. Figure 2 shows an example of a product where the same general design (i.e., same platform) and the majority of the modules/parts were reused by a project with two different product configurations.

Product adaptability is the capability of a physical product to be adapted to satisfy the changed requirements. It is usually achieved by modifying the existing product, such as adding new components and/or modules, replacing or upgrading the existing components/modules with new ones, and reconfiguring the existing components/modules. The user can benefit from product adaptability by reusing most

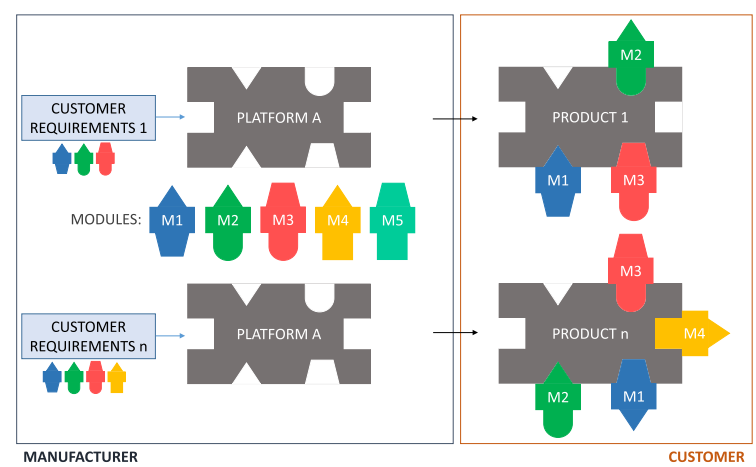

Fig. 2 Design adaptability: deliberately planned design process allows its single execution, while different physical product configuration modes can be later realized 
components/modules of the existing product rather than having to purchase a new product.

According to research, adaptability is important to the customer for two reasons. First, the customer may sometimes be involved in similar projects. Substantial capital, time and expertise are invested in these projects. It is essential to reuse the designs and engineering knowledge as much as possible. For example, a customer orders a number of different products. It is necessary for the customer to have all the products standardized with adaptable equipment solutions due to easier maintenance. Second, due to the complexity of these projects, it is often impossible to predict all design requirements and finalize the design before the construction begins. Figure 3 shows an example of a product that can serve two different end-product modes. High product adaptability enables the customer to adapt the product to his needs in the shortest amount of time with the least resources.

\subsection{Design for changeability}

\subsubsection{Flexibility}

Thomke (1997) defined design flexibility as a function of the incremental cost and time of modifying design choices: the higher the cost and time of modifying a design, the lower the design flexibility. His analysis led to the conclusion that projects characterized by high design flexibility have better performance, i.e., less design effort in terms of person-months and a greater number of changes in physical prototypes, which is an indirect indicator of the ability to incorporate new needs in later stages of development. Thomke and Reinertsen (1998) highlighted that adopting inherently flexible technologies is one of the three strategies for increasing flexibility in NPD; the second is to modify management processes (e.g., progressively lock down requirements and keep multiple backup approaches viable even after concept selection), and the third is to exploit product architecture to

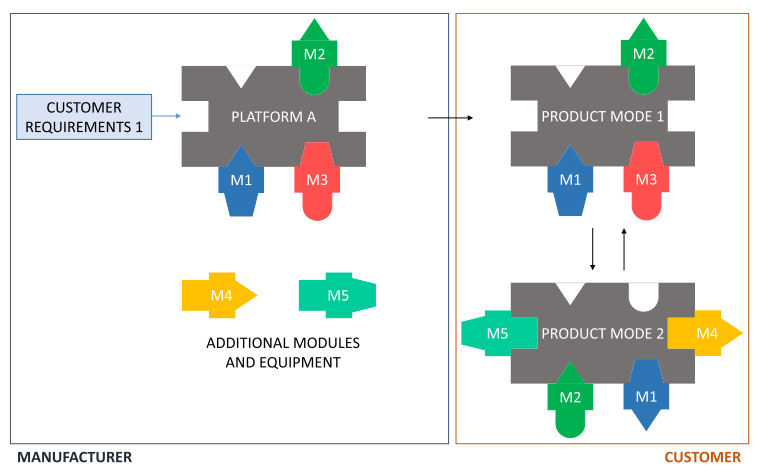

Fig. 3 Product adaptability: example of localized adaptability that allows realization of different product configuration modes during its lifespan reduce the cost and time of modifying a design. MacCormack et al. (2001) introduced the new concept of flexibility in NPD. They identified five basic practices that support flexibility.

\subsubsection{Modularity}

Modular design aims to develop a product architecture consisting of physically detachable units (modules) (Ali and Saed 2002; Gershenson et al. 2003, 2004; Jose and Tollenaere 2005). Because the modules in a modular product are relatively independent, these modules can be designed and manufactured separately. There are numerous advantages to modular products. For example, by carefully modularizing a product, the designs for the earlier models can be used in a new model without any changes. Modular design can also help in creating a range of products with minor variances and allows some components to be used across product variants and product lines due to standardization of the functions and interfaces.

To help understand the complexity of product design and efficiently derive products for customized requirements, the definition of the product architecture has been proposed to decompose a complex system into subsystems or chunks. Ulrich and Eppinger (2012) defined a product architecture as consisting of three elements: (1) the arrangement of functional elements; (2) the mapping relations between functions and physical elements; and (3) the specification of the interfaces among interacting physical components.

2.5.2.1 Platforming Product platforming is a specific solution approach that addresses a subset of the challenges mentioned in previous sections. It focuses mainly on offering high product variety to customers while reducing development and manufacturing costs. In platform design, the common components for a number of products are grouped as the platform to be shared by these products (Jiao et al. 2007; Simpson et al. 2007). The products sharing the same platform usually form a family of products. Platform design is considered as the extension of modular design using the platform - the main module - in all the products of this family. In adaptable design, the functions of different products can be achieved using the platform design approach. When certain functions are required, the modules with these functions are then attached to the platform.

Simpson et al. (2001) identified three categories of platforms. General Platform design generally entails the identification of common attributes within a series of products, otherwise referred to as a product family. Generally, a platform is any set of standardized parameters, which are maintained within a group of products for compatibility. Component Standard Platforms unify manufacturing issues in multiple products using common components whenever 
possible. Modular Platforms use modules from more than one product so that common parts are used whenever possible. Commonality refers to the extent of similarity of the product characteristics from a particular point of view, such as requirements, design features and even physical structures. The most successful application for platform development is dominated by scale-based family design and optimization, wherein commonality represents shared settings of variable values among variants and is assumed to reduce manufacturing complexity and thus improve economic efficiency (Messac et al. 2002; Nayak et al. 2002; Hernandez et al. 2003; Dai and Scott 2006).

\subsection{Initiated changes and emergent changes, change propagation}

Changes are omnipresent in the development and design process of an individualized product (e.g., power transformer) and can occur at any stage of the development of the product. Gautam and Singh (2008) state that there are three types of changes to products: innovation, continuous improvement and forced changes. Continuous improvement and innovation are common productivity options to keep the customer satisfied and willing to buy. Generally, we differentiate between two different sources of change, which are handled in a very similar way but have very different causes:

- Emergent change, caused by the state of the design, where problems occurring across the entire design and throughout the product lifecycle can lead to changes.

- Initiated change, arising from an outside source, typically a new requirement from customers or certification bodies, or initiated by the manufacturer.

Emergent changes occur in response to problems arising during the design process at all levels of integration: in the design of parts, in the design of entire systems, during system integration, during production and assembly or during final testing. The later they occur in the design process, the more costly changes can become. The design of a power transformer is strongly customer-driven, and therefore customer requirements are a major source of initiated changes. Generally, new requirements are known at the beginning of the design process for a particular project, although it often occurs that some of them arise in the course of the design due to unforeseen reasons. Initiated changes usually include customer requirements, problems with past designs, innovations, certification requirements and retrofits.

Systems and parts respond to change in different ways, ranging from systems that do not pass on change to those that amplify change. Eckert et al. (2004) differentiate between four types of change propagation behaviour: constants, absorbers, carriers and multipliers. The way a particular system reacts to change depends on its potential to absorb or multiply change, which can be buffered by change margins. As more and more compromises are made during the design process, these margins decrease as changes are absorbed. A more comprehensive review of engineering change and its propagation can be found in Jarratt et al. (2011) or in Koh et al. (2015), where the authors discuss the idea of using engineering change forecasting to prioritize component modularisation. However, part of the featured research has been focused on methods to reduce product variety through standardization. This is truly a challenging task and even contradictory for one-of-a-kind production environments. The essence of one-of-a-kind products lies particularly in strict compliance with the customer's requirements. Complete subordination to a product's individuality is key in creating value to such enterprises. However, it is also necessary to standardize parts of the product for which the customer usually has no requirements in means of their individuality.

\subsection{Key issues in adaptable design}

Many researchers have argued and illustrated that, the later in the design process changes are made, the greater the costs of the changes are. By waiting until the detailed design is completed to consider configuration optimization, some of the best benefits of the process may be lost. Generally, configuration design can take place at any time between the last part of conceptual design and the early stages of detailed design. Two main design approaches are widely used in configuration design: modular design and product platforming and families (Gu et al. 2004). An approach for achieving some general adaptability is based on the localization of modifications. That is, the architecture of the product is designed in such a way that changes in one place are prevented from propagating into the rest of the product. Such architecture is called "segregated architecture." To make the product/design more adaptable, interfacing between subassemblies is also critical to ensure the adaptability.

In the academic field of engineering design, a large body of research has been published over the last decade addressing various aspects of product family fulfilment, particularly in modular design, product family architecture and product family design and optimization. It is well recognized that platform-based development has a significant effect on the aspects of cost, performance/quality, and variety (Fixson 2007). Modularity and commonality are accepted as two essential characteristics in platform development with multi-functional views, and they may co-exist and are logically inseparable in the product creation process (Jiao et al. 2007). Based on their research, Gu et al. (2009) claim that there have been many design theories and methodologies developed in the past decade to improve design efficiency 
using design knowledge, case-based reasoning, knowledgebased design, design histories and rationales, design repositories and design reuse. Even ontologies were utilized for formalizing domain knowledge in a way to make it accessible, shareable and reusable in design (Darlington and Culley 2008). All of these design methods can help designers consider design adaptability. In the next section, the real industrial background is presented via an illustrative example of a highly complex one-of-a-kind product - a power transformer.

\section{Generalized model of one-of-a-kind product development process transformation according to the principles of adaptability}

The presented generalized model of one-of-a-kind product development is the result of several years of systematic academic research and intensive collaboration with a real industrial production environment. It comprises findings gathered during literature research combined with own experiences gained through author's collaboration with industrial partners. Focus has been put on the development and design process of a complex one-of-a-kind product. On a basis of previously described principles, merged into the master engineering paradigm - changeability - the process has been reconstructed according to an idea of unlimited product individuality, which appear to be a necessary precondition for a successful launch in today's market. Figure 4 presents a generalized framework of such PD process transformation.

As Fig. 4 indicate, a product structure and design processes are inextricably linked between each other. It is of a crucial importance which activity, how much time and how much costs are necessary to conduct a specific design change. Therefore, beside product decomposition also design process decomposition and classification of design activities was done. The design activities that occur more often and are suitable for automation were supported with special tools for faster and more reliable execution. Design activities were systematically analysed, classified, and supported in the most appropriate way. A concurrent adaptation of the product structures and design processes was necessary in several cases. The final result is significant acceleration of design processes, and the reliability of the product design was improved too. We divided the transformation process into three consecutive main phases: the preparation process, classification process and redesign process. The deliberately executed preparation process is of particular importance, while careful product decomposition into relatively independent subassemblies is crucial for a subsequent successful classification process. Decomposition has to yield three main groups of components or design processes (BB1A and
$\mathrm{BB} 1 \mathrm{~B}, \mathrm{BB} 2 \mathrm{~A}$ and BB2B, BB3A and BB3B). Categorization generally follows managerial policy and strategic decisions. Classification process is thus unique for any single company, as it has to be attentively tuned according to the structure and characteristics of an actual product. In the sample company, classification process is the responsibility of the chief design engineers, where they work closely with engineers, responsible for development and management of start-up parts, assemblies, library of standard parts, etc. The core group in design process domain (BB2B) comprises core design processes that enable individual adjustment of product platform with components. The core group in product domain (BB2A) comprises characteristic components that define the product. These components are individually adapted to certain project requirements via controlled process re-engineering. This means that any modification is executed with special concern, as any changes to those components usually mean almost certain accommodations to adjacent, usually subordinated subsystems. In another group, components and design processes that are suitable for standardization are classified (BB1A and BB1B). Those components and design processes are usually very important for the agility of the entire design process. Although they are usually not of great importance to customers, they simplify the structure of the product in means of standardized solutions, especially in detailed design. With their help, any individual project gets a certain degree of large-scale product characteristics and form supplementary standardized part. The last group contains components and design processes that are suitable to be changes (BB3A and BB3B). They form creative part of the design process. Such components are typical for oneof-a-kind production since they increase customer-perceived value and supporting design processes have to execute subordinated design tasks effectively.

Product decomposition and redesign are complex activities which require a systemic approach. The authors propose application of design for changeability based on flexibility, modularity, and platforming. Implementation details are presented in the case study in the Sect. 5 .

In the third, the process re-engineering phase, numerous tools are encouraged to be used: case-based reasoning, knowledge-based design, ontologies, design reuse and others. A fundamental distinction can be drawn between two types of models:

- Planning models provide transparency with regard to the creative value-added generated by engineers and thus make it possible for complex systems to be built. An example of a planning model would be a schematic used by an engineer to explain how he or she has implemented appropriate functions to meet the requirements placed on a system. As such, the model contains the engineer's knowledge. 


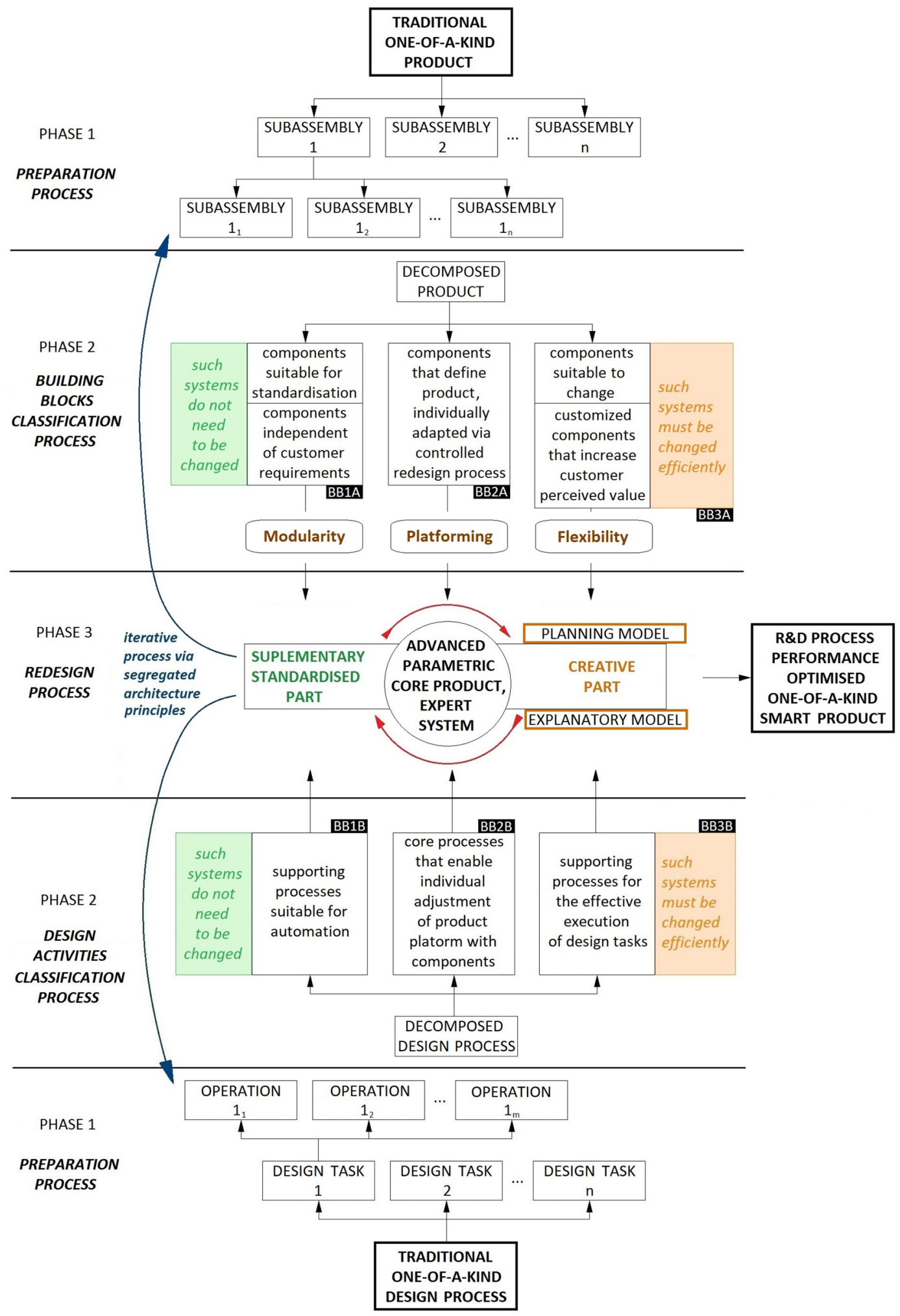

Fig. 4 Proposed generalized framework of a highly efficient one-of-a-kind PD product transformation according to the principles of adaptability 
- Explanatory models describe existing systems to acquire knowledge about the system through the model. This typically involves using different analysis processes, such as simulation. Explanatory models are often used to validate engineers' design choices.

Models offer huge potential - and not only in the context of smart industry. For example, they allow the risks involved in a project to be reduced through early detection of errors or early verification of the demands placed on the system and the ability of proposed solutions to meet these demands. They can also provide a transparent information flow that enables more efficient engineering by improving interdisciplinary cooperation and facilitating more consistent engineering data. One-of-a-kind research and development (R\&D) has to be continuously improved via iterative process, during which designers perform back loops and repeat phase 1 , phase 2 and phase 3 occasionally to meet the desired rate of product development.

The generalized model summarizes the whole approach and proposed principles in one page. The industrial example of the large power transformer demonstrates and validates application of changeability in product development through: flexibility, modularity, and platforming and product family design.

\section{Real industrial background and sample company presentation}

A sample company is a renowned producer of large power transformers with a one-of-a-kind business model. The design of each new power transformer (Fig. 5) suits an adaptive type of design (Duhovnik and Tavčar 2015). When a new design problem arises, it is solved through the modification of an existing design rather than performing the design process from scratch. Due to the complexity, associated cost and general uncertainty of performing the creative design process, significant value exists in reusing existent design information. Each customer approaches the manufacturer with his or her own set of specific requirements. The basic working principles, as well as the peripheral functional requirements, are fully known, and the design model is well defined. The design begins from the same baseline every time, which is the selection of the appropriate parametric 3D model layout of each respective subassembly. The design and functional characteristics of individual assemblies are generally known in advance. Parametric models consist of parametric subassemblies and parts, the design of which is well-considered and based on experience and knowledge of the company, as well as a number of standard components. The essence of the problem for any new design is thus expressed in the search for a new technical shape that would optimally meet the individual requirements of each specific client. Despite a well-structured and content-rich parametric library of start-up assemblies and parts, each new individual contract demands a modification of numerous details, which makes each final product unique. The individualization process includes parametric change of prepared-in-advance components and sometimes a certain degree of completely new designed components.

\section{Application of changeability in one-of-a-kind product development - generalized framework model validation with the case study}

In this section, application of changeability in real one-of-akind product development is presented via three main principles: flexibility (E1.1), modularity (E1.2) and platforming (E1.3) (Fig. 4). Each principle is explained through an
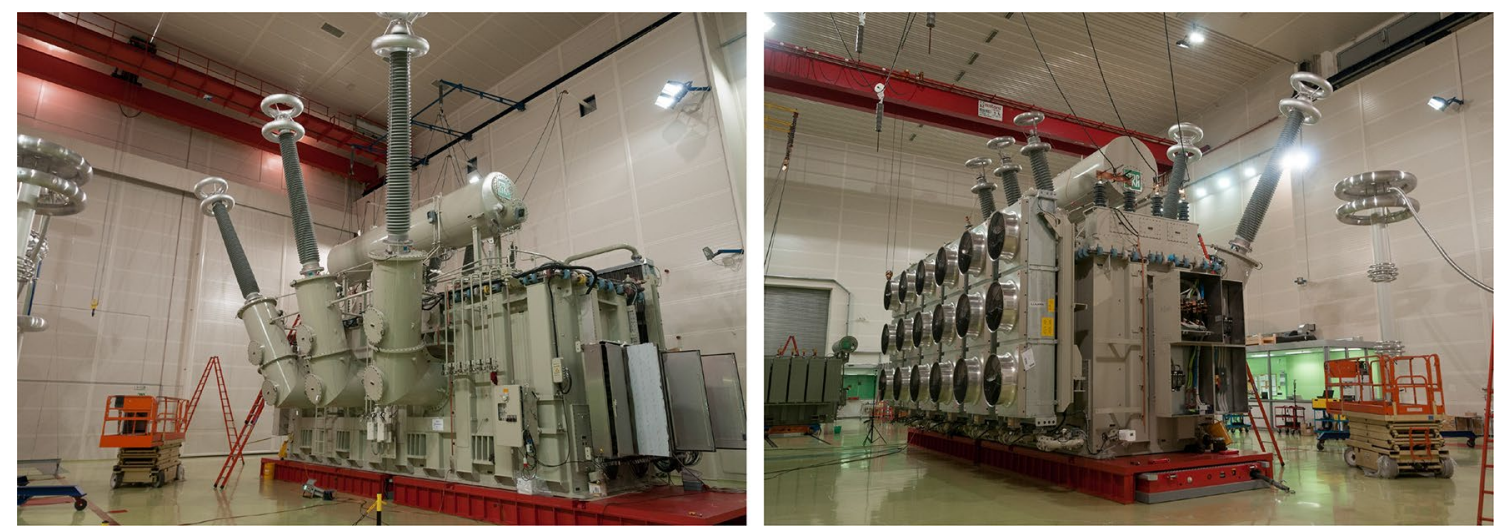

Fig. 5 An example of two power transformers, where the same functionality is realized with two very different shape models. Agile PD plays a key role in company competitiveness 
illustrative example of application to a real industrial environment during the case study. This section represents a core of the applicative research and a basis for further research activities and validation of a generalized framework of a highly efficient one-of-a-kind PD process transformation according to the principles of adaptability, as proposed in Sect. 3. Methodology of application of changeability in oneof-a-kind product development during case study is presented in Fig. 6. In the flowchart activities are presented in appropriate chronological order. On the right side of the Fig. 6, outcomes of each phase are stated. Initial process flow mapping is the foundation of all further activities. Results of the company business model analysis enable preparation of product structure and design process transformation guidelines. These guidelines may be specific for each individual company, taking into account its profile and product range. Design process and product structure transformation is first applied and evaluated as a pilot project. Collected experiences and results of evaluation are basis for preparing strategy for implementation of improved product changeability, which should be tailored to each individual company. Product changeability considers flexibility, modularity, and platforming domain. Implementation towards improved changeability follows in several steps because it can be time consuming.

Generalized model, presented in Fig. 4 was created not only on the basis of a literature review, but in several implementation steps. The model was set up first and then this model was confirmed in the individual steps on the basis of overall evaluation. During the implementation, the model was validated and in some cases supplemented if necessary.

\subsection{Flexibility (E1.1)}

Table 1 combines five basic practices with observations and experience gained during a case study. The development and design process in sample company underwent extensive renovation, during which the below stated tools, methods and measures proved to be very useful in the one-of-a-kind business environment.

\subsection{Modularity (E1.2)}

An aspect that greatly influences adaptability, flexibility and agility is the concept of modularity. The underlying principle of a segregated architecture is to prevent changes in some part of the product from propagating to the rest of it. A segregated architecture encourages the development of selfcontained and relatively independent assemblies or modules that can be detached, modified, relocated, and replaced easily. The operation of modularity analysis at different development stages is the strategic result of a search for potential common technical solutions. The earlier modularisation process provides more freedom to define architectural content and allocates the function-component mapping relationship, as shown in Fig. 7. With one-of-a-kind product development during a case study, research team was especially focused on physical and parametric modularity.

Functional modularisation relaxes the constraint of the predefinition of sub-module level components and offers a fundamental approach for proactive platform development. Assuming the basic physical element as fixed, physical modularisation generates the modular product architecture by re-arranging these elements into larger units (modules) and is adopted for product or platform redesign. Parametric modularity considers the product structure as essentially fixed, and the product characteristics are varied only within the boundaries of the individual elements or parameters. This type of approach provides the least freedom to change the product structure and only pursues a certain commonality at the detailed module/assembly design stage.

In a one-of-a-kind PD and design process, usually only physical and parametric modularity exist according to the nature of the variation or adaptive design process. Figure 8 presents the synergy of physical and parametric modularity, which was, during this research and case study found to be crucial for the transformation of a traditional development and design process into a highly efficient operation of almost unlimited design flexibility and short time-to-market performance. With systematic implementation of modularity principles into its business model, a sample company gained valuable progress in the field of process excellence. It took a company several years to transform different segments of the PD process from a traditionally organized process, where every subsystem is designed individually, into a structured, three-level process, where subsystems are mutually linked with a substantial number of self-aware components. On the first level (configuration design/physical modularity), a general product architecture is defined via selection of an appropriate platform for each product subassembly. The level-1 smart loop enables an efficient configuration design process because all platforms are interchangeable due to the unified connecting interfaces. The level-2 smart loop enables an exchange of parameters between the first and third levels. On the third level (detailed design/parametric modularity), the detailed product architecture is set via the flow of parameters, where parametric modularity enables effective design iterations in the case of late design changes.

\subsection{Platforming and product family design (E1.3)}

During this research, a scale-based platform approach for creating variants with different performance requirements by 'stretching' or 'shrinking' the platforming elements has been proved to be an efficient tool for custom or small-scale PD. Figure 9 shows novel structure of a sample assembly, characterised by standard part (left) and creative part (right), which ensures quick adaptation to 


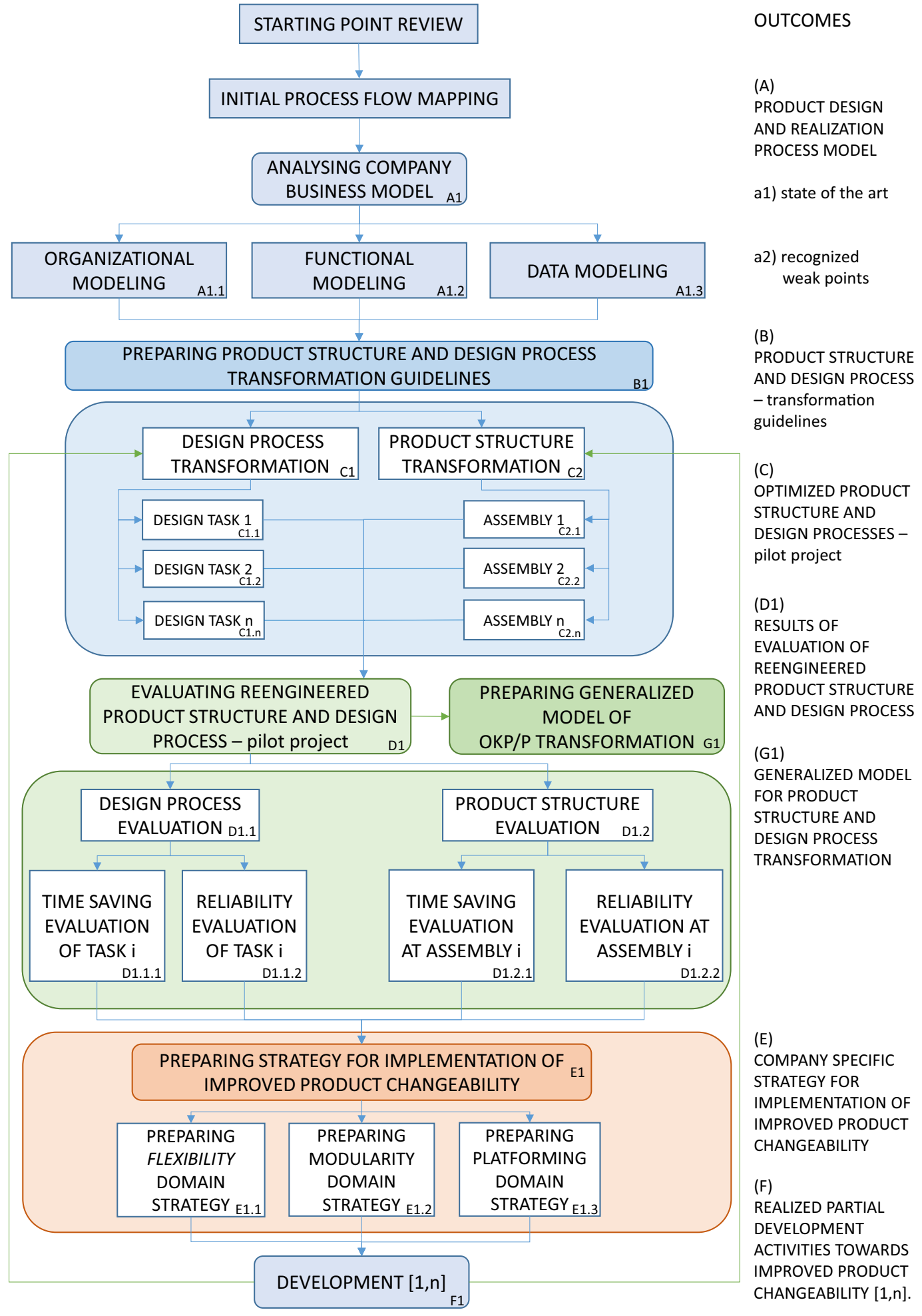

Fig. 6 Methodology of application of changeability in one-of-a-kind product development - case study 


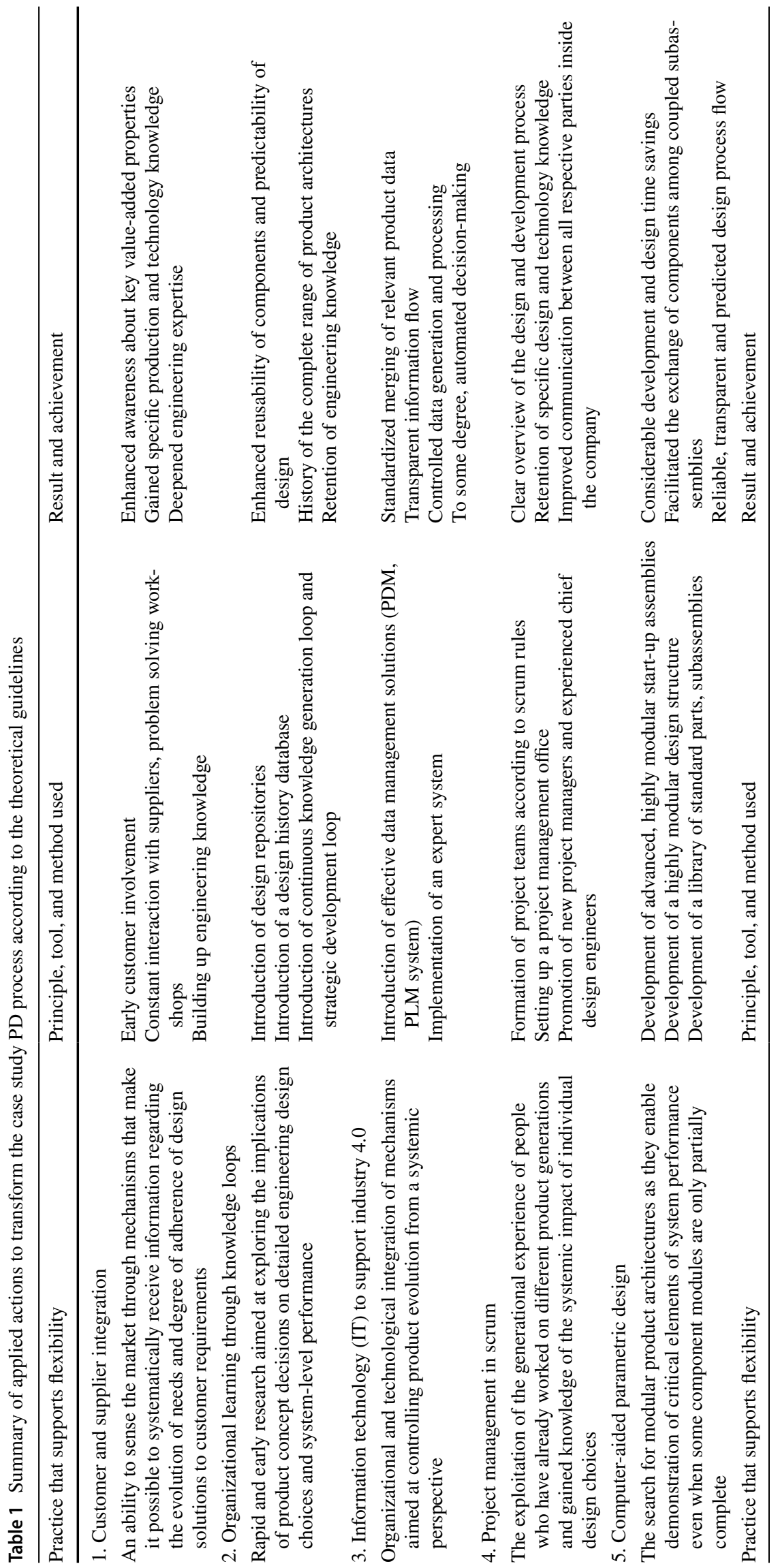




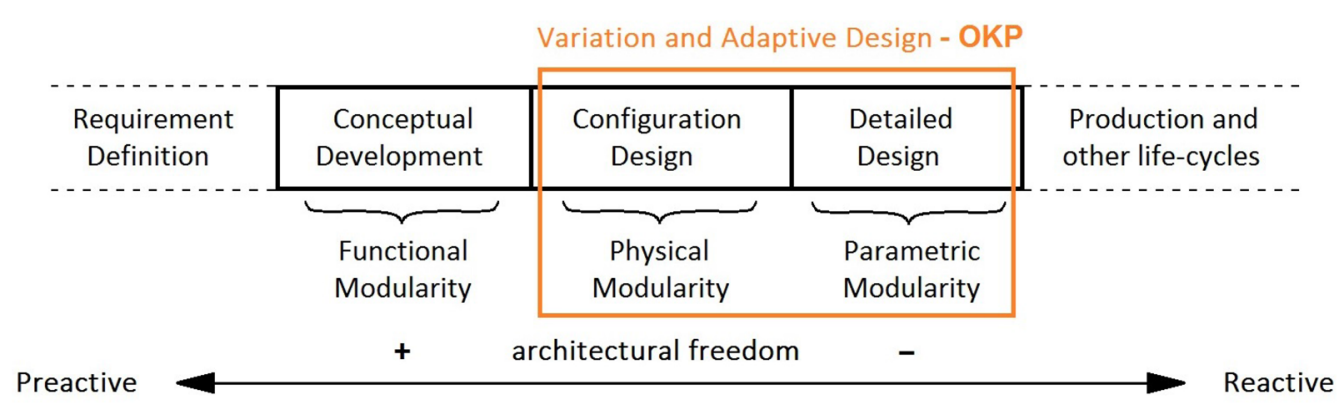

Fig. 7 Modularity occurrence along the PD process

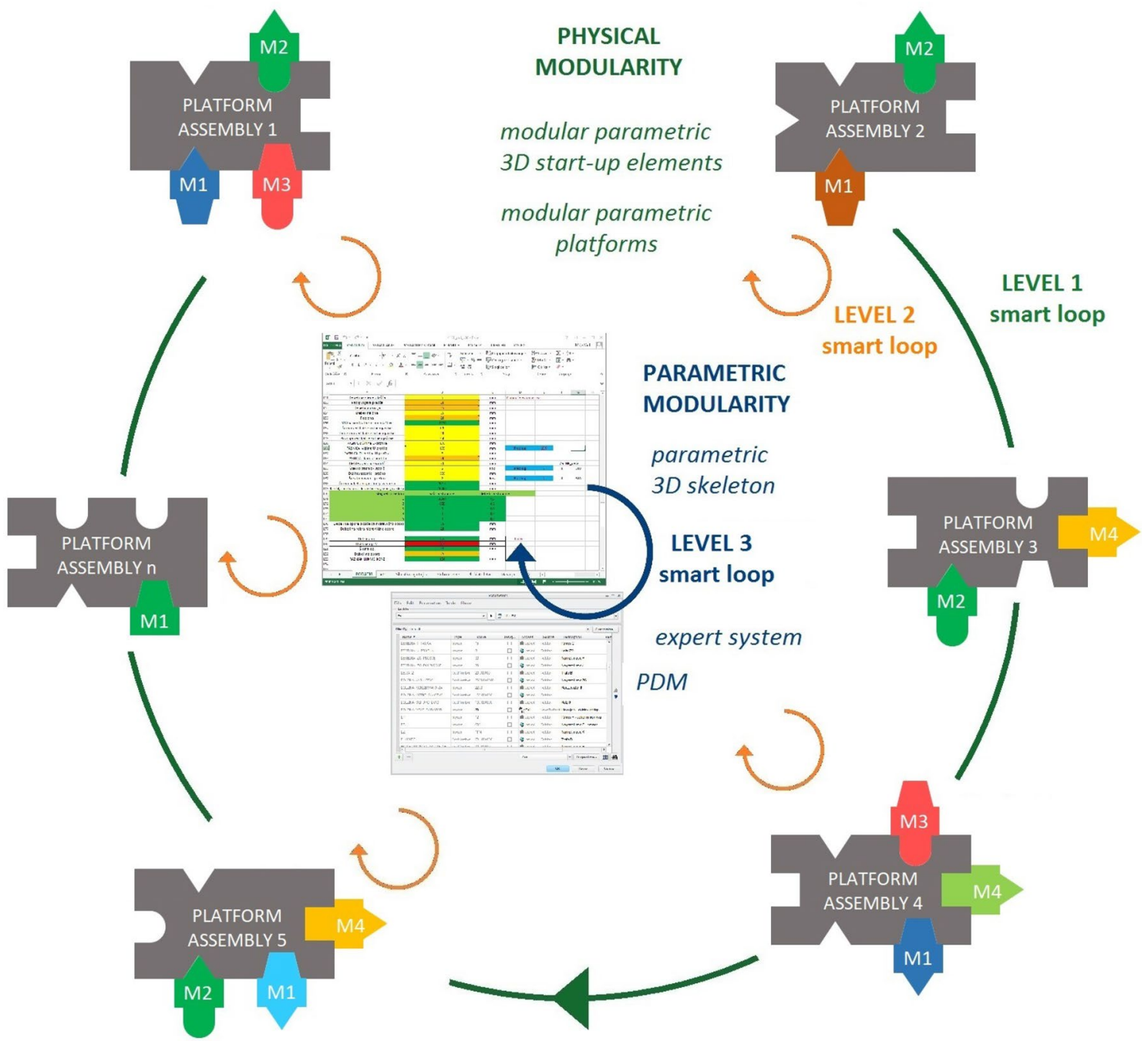

Fig. 8 Synergy of physical and parametric modularity in a highly individualized business environment (sample company) with smart loops on different levels. During a case study, subsystems have been mutually linked with a substantial number of self-aware components.
Typical major subassemblies of a power transformer (from the upper left, clockwise): tank, active part, cover, equipment, cooling system and conservator 

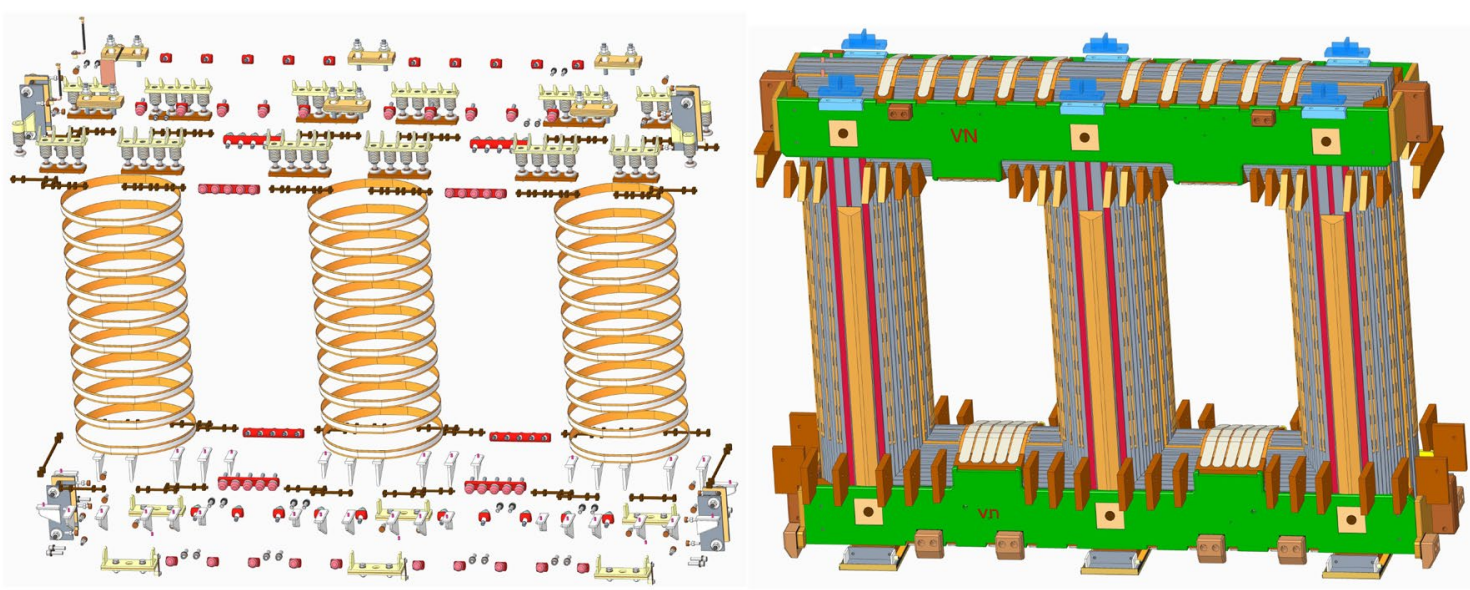

Fig. 9 Novel structure of a sample assembly (magnetic circuit), characterised by standard part (left) and creative part (right), which ensures quick adaptation to new requirements

new requirements. Figure 10 shows an example of a fully parametric 3D platform, which achieved substantial design time savings, up to $40 \%$ in comparison to the former, stepby-step design process.

Table 2 shows a detailed list of savings, which were recognized as a direct consequence of the implied renovation. The values in this table were obtained via the performance analysis of conducted projects of a sample subassembly (in this case, a magnetic core - Figs. 9, 10) during a 1-year test period. Although results for different subassemblies may vary, a similar general trend was noticed.

Figure 11 shows the number of completed projects in mechanical design department for the studied product segment. The analysis clearly shows a considerable drop in necessarily engineering changes, which are the consequence of non-optimal product design. The results are in direct association with the enhanced robustness of the development and design process.

The improved performance (Table 2) and less engineering changes (Fig. 11) clearly validate advantages of design for changeability that was implemented on the case of large power transformers according to the generalized model presented in Sect. 3.

During case study research, team observed that certain limitations nevertheless exist. One of the main issues in the evolution process described above is finding an optimum degree to which design reuse should be limited. Exaggeration in this field can lead into less creative development and design process, which further causes design fixation and cursory exploration of possible design alternatives. Presented research indicates that an optimum degree of standardization combined with design reuse may be different for any specific production environment.

\section{Discussion and assessment}

The theory of changeability has been a widely studied engineering paradigm in the past two decades because it represents a fundamental and universal engineering approach to efficient NPD processes in versatile production environments. Although the majority of research work in the professional literature has been conducted in the fields of mass industry, there has been noticed a tendency to shift the research activities to an individualised production environment in recent years. We estimate that agility is especially interesting in the field of customized products, as quick adaptation to customer requirements and the ability to use the existing design solutions as much as possible are crucial for commercial success. Successful management of never-ending engineering changes appears to be the most important aspect in this field. Accordingly, introduction of changeability into a highly individualized production environment is mostly about enhancing the robustness of the NPD process, which leads to minimization of rework activities, reputation on the market and overall excellence of a company. The featured research aims to deliver a generalized framework of a one-of-a-kind PD process transformation according to the principles of changeability. The case study demonstrates how companies in such a specific business environment can improve their profitability through the utilization of changeability concepts.

Introduced framework has been developed, tested and proved to be efficient in a highly individualized industrial case, in which every single order is specific and contains customer-tailored solutions. Table 2 shows a detailed list 

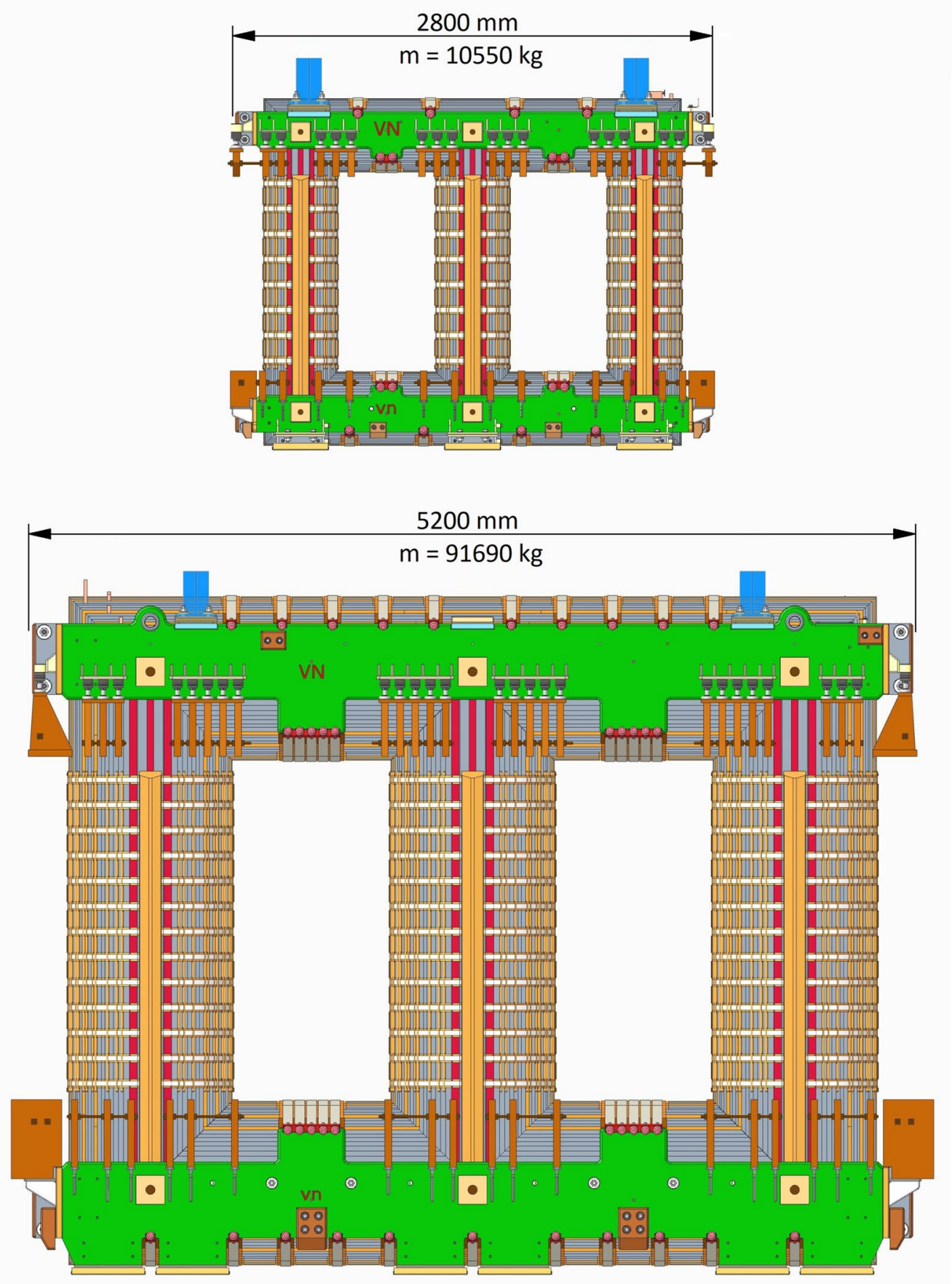

Fig. 10 Fully parametric 3D platform of a magnetic circuit; both models were created from the same parametric model. The scalable platform with built-in modular attributes enables the model to be cus-

of savings, which were recognized as a direct consequence of the implied renovation. The values in this table were obtained via the performance analysis of conducted projects of a sample subassembly (in this case, a magnetic core - (Figs. 9, 10) during a 1-year test period. Figure 11 shows the number of completed projects in mechanical tomized and adjusted according to new design parameters and customer specifications in a considerably short amount of time. The efficient iterative process enables late design decisions

design department for the studied product segment. The analysis clearly shows a considerable drop in necessarily engineering changes, which are the consequence of nonoptimal product design. The results are in direct association with the enhanced robustness of the development and design process. 
Table 2 Complete list of savings, resulting in PD process renovation according to agile principles

\begin{tabular}{llllllll}
\hline Item & $\mathrm{T}_{\mathrm{PREP}}[\mathrm{min}]$ & $\mathrm{T}_{3 \mathrm{D}}[\mathrm{hrs}]$ & $\mathrm{T}_{\mathrm{DRW}}[\mathrm{hrs}]$ & $\mathrm{T}_{\text {TOTAL }}$ [hrs] & EC rate [\%] & $\begin{array}{l}\text { Project rate [/ } \\
\text { year] (T) }\end{array}$ & $\begin{array}{l}\text { Project rate } \\
{[/ \mathrm{year}](\mathrm{R})}\end{array}$ \\
\hline Before implementation & 60 & 16 & 24 & 40 & 5 & 45 & 40 \\
After implementation & 10 & 5 & 18 & 23 & 1 & 78 & 45 \\
Performance improvement & 50 & 11 & 6 & 17 & +33 & 5 \\
& $+500 \%$ & $+220 \%$ & $+33 \%$ & $+74 \%$ & $+400 \%$ & $+73 \%$ & $+13 \%$ \\
\hline
\end{tabular}

$T_{P R E P}=$ time for preparation. All necessary data for an uninterrupted design process are gained during this time

$T_{3 D}=$ time necessary for the completion of a 3D design of the featured assembly (magnetic core)

$T_{D R W}=$ time necessary for the completion of a corresponding technical documentation

$T_{\text {TOTAL }}=$ total design time $\left(\mathrm{T}_{3 \mathrm{D}}+\mathrm{T}_{\mathrm{DRW}}\right)$

$E C$ rate $=$ percentage of realized projects where engineering change was necessary (rework)

Project rate $(T)=$ number of realized projects per year per person (theoretical projection)

Project rate $(R T)=$ number of realized projects per year per person (actual). In 2013, 2 engineers designed 80 projects in total. In 2018, 3 engineers designed 135 projects in total, where development activities (they run in parallel with projects) have taken approximately 3-5\% of total time available

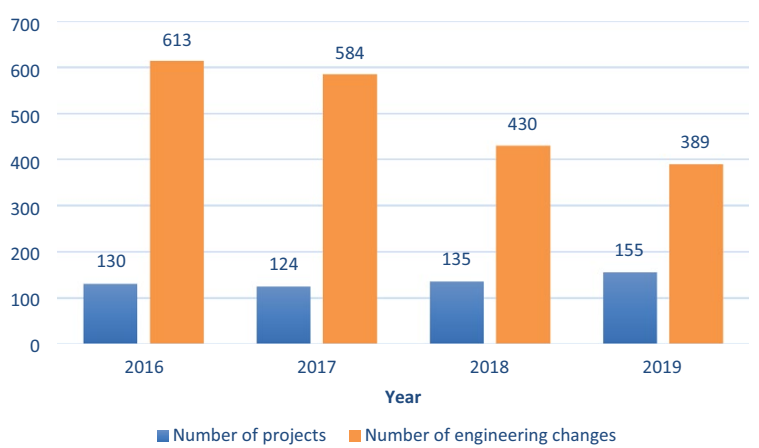

Fig. 11 Engineering changes per year in comparison to completed projects

The conducted design process re-engineering and product redesign for changeability is complex and long-term activity. Several departments and experts from different disciplines must be actively involved. Due to the complexity and associated cost, re-engineering can be implemented only with strong support from top management. The generalized model and case study present systemic approach and principles, however several implementation details and supporting tools must be determined in the context of the specific application.

We claim that the proposed framework would therefore also be useful in small and medium-batch production. According to our experience, the greater the individuality and smaller the batch size, the shorter the development and design lead-time. Therefore, we argue that the proposed framework can further be developed in the case that development and design lead-time is longer. The expert system, for example, can further be expanded with additional tools to support software autonomous decision-making, for example, with change propagation models, part history lists, integrated FMEA analyses, etc., which would enable an even more advanced automatic compatibility check for different product configurations already in the early development phase. We strongly encourage the management of small- and medium-sized enterprises that provide customized, one-ofa-kind products to start with re-development of their product development and design processes according to the proposed framework. Feedback information via published studies would be an important and valuable contribution to further development of this specific branch of otherwise broad field of smart industry doctrine.

\section{Conclusion}

Design for changeability, a design strategy developed to cope with engineering changes, incorporates the following four aspects: adaptability, robustness, agility and flexibility. System architectures characterized by these attributes will yield great enhancements. Technology insertion throughout the entire system lifecycle to ensure superior system capabilities and customized functionality is possible. Upgrade opportunities and the ease of customization lead to high attractiveness to customers or stakeholders. Additional principles, such as independence, modularity, scalability or design reuse, support the implementation of the four abovementioned attributes and thereby enable rapid responsiveness to emerging and changing markets and efficient product adaptation to numerous individual customer requirements.

In the article, an extensive transformation of an illustrative example of a one-of-a-kind product according to the principles of changeability is presented. The focus of the comprehensive renovation has been put on establishing the 
above-mentioned four main aspects of the product changeability in the specific, highly individualized production environment. Design reuse aims to maximize the value of customization efforts by reusing successful past design information in whole or in part for future designs. The ultimate aim of design reuse is to assist the designer in the development of high-quality products that meet all customer requirements while expending the least amount of effort and resources. Design reuse as a concept was developed and researched extensively in the computer science and software development fields and later implemented in various fields of mass production environments. The valuable contribution of the paper is the demonstration that the transfer of optimization principles, techniques and tools, known from the mass industry, into a highly individual type of production is possible and can be efficient and beneficial in a great manner when certain rules and limitations are taken into consideration.

The conducted research demonstrates that the exposed issue is complex, and therefore its professional width requires the cooperation of the entire company. In practice, successful change management means finding the most reliable and the least time-consuming way to design a product that would fully meet the customer's requirements and preferences. The conducted case study has revealed that this is possible by developing holistic solutions and designing standardized systems, combined with highly efficient platform designs that consider modularity and scalability coupled with a consideration to reduce indirect costs. The results of the featured research are promising in multiple aspects and offer various opportunities for further development. The proposed framework (Fig. 4) has been designed as a three-stage transition process. In the preparation process (phase 1), the complete product has to be decomposed to the part level. In-depth analysis enables a competent classification process (phase 2 ), where we suggest that components are classified into three basic branches: components that create the core of the product, components that are appropriate to undergo a standardization process, and components that represent the creative part, which has to be changed to add value in terms of a customized product. The last phase is where the real development and optimization begins, for which the analysis, presented in the previous section, has proved that, with deliberately chosen principles, tools and methods, the traditional PD process can be transformed into an agile, highly efficient operation. The proposed framework is generalized, which makes it directly applicable in similar business environments and thus helpful for establishing the best-practice guidelines for promoting competitiveness in one-of-a-kind PD processes.

Funding Open access funding provided by Lund University.
Open Access This article is licensed under a Creative Commons Attribution 4.0 International License, which permits use, sharing, adaptation, distribution and reproduction in any medium or format, as long as you give appropriate credit to the original author(s) and the source, provide a link to the Creative Commons licence, and indicate if changes were made. The images or other third party material in this article are included in the article's Creative Commons licence, unless indicated otherwise in a credit line to the material. If material is not included in the article's Creative Commons licence and your intended use is not permitted by statutory regulation or exceeds the permitted use, you will need to obtain permission directly from the copyright holder. To view a copy of this licence, visit http://creativecommons.org/licenses/by/4.0/.

\section{References}

Al-Ashaab A, Golob M, Urrutia UA, Gourdin M, Petritsch C, Summers M, El-Nounu A (2016) Development and application of lean product development performance measurement tool. Int J Comput Integr Manuf 29(3):342-354

Ali KK, Saed MS (2002) Product design for modularity. Kluwer Academic

Brettel M, Friederichsen N, Keller M, Rosenberg M (2014) How virtualization, decentralization and network building change the manufacturing landscape: an industry 40 perspective. Internat J Mech Aero Indust Mech Manuf Eng 8:1

Chen J, Reilly R, Lynn G (2012) New product development speed: too much of a good thing? J Prod Innov Manag 29(2):288-303

Dai Z, Scott MJ (2006) Effective product family design using preference aggregation. J Mech Des 128:659-667

Darlington MJ, Culley SJ (2008) Investigating ontology development for engineering design support. Adv Eng Inform 22(1):112-134

Dixon J, Poli C (1995) Engineering design and design for manufacture. Field Stone

Du X, Jiao J, Tseng M (2001) Architecture of product family: fundamentals and methodology. Concurr Eng: Res Appl 9(4):309-326

Duhovnik, J, Tavčar J (2015) Concurrent engineering in machinery, Chapter 22. In: Stjepandić J, Wognum N, Werhagen WJC (Eds.) Concurrent engineering in the 21st century: foundations, developments and challenges. Springer.

Eckert C, Clarkson PJ, Zanker W (2004) Change and customisation in complex engineering domains. Res Eng Design 15(1):1-21

Faller C, Feldmüller D (2015) Industry 4.0 learning factory for regional SMEs. The 5th conference on learning factories 2015, Procedia CIRP, 32: 88-91.

Fey V, Rivin E (2005) Innovation on demand: new product development using TRIZ. Cambridge University Press

Filho MF, Liao Y, Loures ER, Canciglieri O (2017) Self-aware smart products: systematic literature review, conceptual design and prototype implementation. Proc Manuf 11:1471-1480

Fixson K (2007) Modularity and commonality research: past development and future opportunities. Concurr Eng Res Appl 15(2):85-111

Fletcher D, Gu P (2005) Adaptable design for design reuse. In: Second CDEN international conference on design education, innovation, and practice, Canada.

Fricke E, Schulz AP (2005) Design for changeability (DfC): principles to enable changes in systems throughout their entire lifecycle. Syst Eng 8(4):342-359

Gautam N, Singh N (2008) Lean product development: maximizing the customer perceived value through design change (redesign). Int J Prod Econ 114(1):313-332

Gershenson JK, Prasad GJ, Zhang Y (2003) Product modularity: definitions and benefits. J Eng Des 14(3):295-313 
Gershenson JK, Prasad GJ, Zhang Y (2004) Product modularity: measures and design methods. J Eng Des 15(1):33-51

Ghobakhloo M, Azar A (2018) Business excellence via advanced manufacturing technology and lean-agile manufacturing. J Manuf Technol Manag 29(1):2-24

Gu P, Rao H, Tseng MM (2001) Systematic design of manufacturing systems based on axiomatic design approach. Ann CIRP 50(1/2001):299-304

Gu P, Hashemian M, Nee AYC (2004) Adaptable Design. Manuf Technol 53(2):539-557

Gu P, Xue D, Nee AYC (2009) Adaptable design: concepts, methods, and applications. Proc Instit Mech Eng Part b: J Eng Manuf 223(11):1367-1387

Hashemian M, Gu P (1996) A function representation scheme for conceptual mechanical design. Proceedings of the 11th International Conference on Engineering Design, ICED97, 2:311-314, August 19-21, 1997, Tampere, Finland

Hermann M, Pentek T, Otto B (2016) Design principles for Industrie 4.0 scenarios. Hawaii international conference on system sciences (HICSS), IEEE Computer Society, pp. 3928-3937.

Hernandez G, Allen JK, Mistree F (2003) Platform design for customizable products as a problem of access in geometric space. Eng Optim 35(3):229-254

Jarratt TAW, Eckert CM, Caldwell NHM, Clarkson PJ (2011) Engineering change: an overview and perspective on the literature. Res Eng Design 22(2):103-124

Jiao J, Simpson TW, Siddique Z (2007) Product family design and platform-based product development: a state-of-the-art review. J Intell Manuf 18(1):5-29

Jose A, Tollenaere M (2005) Modular and platform methods for product family design: literature analysis. J Intell Manuf 16(3):371-390

Kagermann H, Wahlster W, Helbig J (2013) Recommendations for implementing the strategic initiative INDUSTRIE 4.0. Industrie 4.0 Working Group of Acatech

Koh ECY, Förg A, Kreimeyer M, Lienkamp M (2015) Using engineering change forecast to prioritise component modularisation. Res Eng Design 26(4):337-353

Leite M, Braz V (2016) Agile manufacturing practices for new product development: industrial case studies. J Manuf Technol Manag 27(4):560-576

Leite M, Baptista AJ, Ribeiro AMR (2016) A road map for implementing lean and agile techniques in SMEs product development teams. Int J Prod Dev 21(1):20-40

Liao Y, Deschamps F, Loures EFR, Ramos LFP (2017) Past, present and future of Industry 40-A systematic literature review and research agenda proposal. Internat J Prod Res 55912:3609-3629

Liu Z, Wong YS, Lee KS (2010) Modularity analysis and commonality design: a framework for the top-down platform and product family design. Int J Prod Res 48(12):3657-3680

Lu Y (2017) Industry 4.0: a survey on technologies, applications and open research issues. J Ind Inf Integr 6:1-10

MacCormack A, Verganti R, Iansiti M (2001) Developing products on internet time: the anatomy of a flexible development process. Manage Sci 47(1):133-150

Martin MV, Ishii K (2000) Design for variety: a methodology for developing product platform architectures. Proc DETC 2000/ DFM-14021, ASME
Messac A, Martinez MP, Simpson TW (2002) Effective product family design using physical programming. Eng Optim 34:245-261

Nayak R, Chen W, Simpson TW (2002) A variation-based method for product family design. Eng Optim 34(1):65-81

de Neufville R, Scholtes S (2011) Flexibility in engineering design. MIT Press

Pahl G, Beitz W (1988) Engineering design: a systematic approach. Spinger-Verlag

Potdar PK, Routroy S, Behera A (2017) Agile Manufacturing: a systematic review of literature and implications for future research. Internat J 24(7):2022-2048

Qudrat-Ullah H, Seong BS, Mills BL (2012) Improving high variablelow volume operations: an exploration into the lean product development. Int J Technol Manage 57(1-3):49-70

Sand J, Gu P, Watson G (2002) HOME: house of modular enhancement for product modularization. Concurr Eng Res Appl 10(2):153-164

Sangwa NR, Sangwan KS (2018) Development of an integrated performance measurement framework for lean organizations. J Manuf Technol Manag 29(1):41-84

Schuha G, Gartzena T, Soucy-Bouchardb S, Bassea F (2017) Enabling agility in product development through an adaptive engineering change management. Procedia CIRP 63:342-347

Siddique Z, Rosen DW (2000) Product family configuration reasoning using discrete design spaces. Proceedings of DETC 2000/DTM14666, ASME

Simon HA (1996) Sciences of the artificial. MIT Press

Simpson TW, Maier JRA, Mistree F (2001) Product platform design: method and application. Res Eng Design 13(1):2-22

Simpson TW, Siddique Z, Jiao J (eds) (2007) Product platform and product family design, methods and applications. Springer

Stjepandić J, Wognum N, Werhagen WJC (eds) (2015) Concurrent engineering in the 21 st century: foundations, developments and challenges. Springer

Suh NP (2001) Axiomatic design: advances and applications. Oxford University Press

Tavčar J, Duhovnik J (2005) Engineering change management in individual and mass production. Robot Computer-Integ Manuf 21(3):205-215

Thomke SH (1997) The role of flexibility in the development of new products: an empirical study. Res Policy 26(1):105-119

Thomke SH, Reinertsen D (1998) Agile product development: managing flexibility in uncertain environments. Calif Manage Rev 41(1):8-30

Turner R (2017) The impact of agile and lean on process improvement CrossTalk. J Defense Softw Eng 30(2):4-7

Ulrich KT, Eppinger SD (2012) Product design and development. McGraw-Hill

Varl M, Duhovnik J, Tavčar J (2016) Towards a model for robust design and design process in one-of-a-kind production of large power transformers. Internat J Agile Syst Manag 9(1):67-88

Wang S, Wan J, Zhang D, Li D, Zhang C (2016) Towards smart factory for industry 4.0: a self-organized multi-agent system with big data based feedback and coordination. Comput Netw 101:158-168

Yan HS, Xue CG (2007) Decision-making in self-reconfiguration of a knowledgeable manufacturing system. Int J Prod Res 45(12):2735-2758 